\title{
Simple reaction time as a function of preparation for a subsequent choice reaction time task
}

\author{
JOSEPH E. KOVESDI and STEFAN SLAK \\ University of Toledo, Toledo, Ohio 43606
}

\begin{abstract}
The purpose of this study was to test the hypothesis that an increase in the number of alternatives in the choice reaction time task would lengthen the reaction time in the immediately preceding simple reaction time task because of higher attentional preparation demand. The simple reaction time task involved an auditory click and was performed between the warning light and the visual choice reaction time task. The hypothesis was confirmed. The increase in simple reaction time as a function of information load of the subsequent choice reaction time task was explained in terms of an increased amount of commitment of limited-capacity attentional system and was interpreted as signifying that there is at least partial parallel processing of the two tasks. The relation of these results to some recent data on the effect of expectancy and limited-capacity short-term memory was discussed.
\end{abstract}

The effect of stimulus probability on choice reaction time has long been known. In the context of information theory approach, choice reaction time was shown to be a linear function of the information value of the stimulus (Hick, 1952; Hyman, 1953). When alternative stimuli are equiprobable, the relation reduces to reaction time as a linear function of the logarithm of the number of alternatives. There is an obvious relationship between the objectively definable stimulus probability and the more subjective expectancy of the stimulus. The interest shifted directly to the effect of stimulus expectancy (e.g., Miller \& Anbar, 1981; E. Smith, 1968). Fitts and Switzer (1962) have demonstrated the importance of expectancy in a choice reaction time task by showing that the time of response to the same stimulus was affected by the number of stimuli that the subject thought could occur, even though the actual number of possible stimuli was the same. The effect of the number of alternatives depended on the subject's expectancy. Expectancy has been shown to be an effective variable in a variety of tasks. Neely (1977), using a lexical decision task, and Posner and Snyder (1975), using a letter-matching task, have shown facilitation of reaction when the subjects' expectancies are met and inhibition of reaction when the expectancies are not met. Both studies have concluded that the effects are mediated by the commitment of a limited-capacity attentional system. The effect of expectancy on the choice reaction time implies the possibility that the subjects' preparation is important and that the amount of preparation the subject invests in the reaction process influences reaction time.

Single-channel theory of attention inspired research on the psychological refractory period. If two stimuli, $S_{1}$ and $S_{2}$, both requiring a response, are presented in close succession, reaction time for the second stimulus will be delayed, so that $\overline{\mathrm{T}}(2)=\overline{\mathrm{T}}_{1}+\overline{\mathrm{T}}_{2}-$ ISI (for ISI $\leqslant \bar{T}_{1}$ ), where ISI is the time interval between $S_{1}$ and $S_{2}, \bar{T}_{1}$ and $\bar{T}_{2}$ are the average reaction times for $S_{1}$ and $S_{2}$ presented in isolation, and $\bar{T}(2)$ is the reaction time for $S_{2}$ preceded by $S_{1}$ (Sanders, 1979 , p. 427). M. Smith (1969) found that an increase in the number of alternatives for $S_{1}$ delayed $\bar{T}(2)$ further. "If only the first response is specifically prepared in successive reaction processes, $T_{2}$ is delayed as a result of the fact that the response to $S_{2}$ is unprepared. This point is often used to explain the delay of $\mathrm{T}(2)$ in ISI $\geqslant \mathrm{T}_{1}$ " (Sanders, 1979, p. 428). While the idea of the psychological refractory period assumes a single-channel attentional system and serial processing, the concept of preparation does not. If the preparations for $S_{1}$ and $\mathrm{S}_{2}$ partially overlap, that is, if there is at least partial parallel processing of the two stimuli, one would predict that the preparation of $S_{2}$ would retard $T_{1}$. Furthermore, greater information value of $S_{2}$ would require a greater amount of preparation, thus increasing the amount by which $T_{1}$ would be retarded. It is the purpose of the present study to test the hypothesis that an increase in the number of alternatives in the choice reaction time task will result in longer simple reaction time for a preceding stimulus.

\section{METHOD}

\section{Subjects}

Twenty-four volunteer undergraduate students of both sexes were assigned to all experimental conditions.

\section{Apparatus and Stimuli}

A click produced by a .2 -sec burst of electrical current generated by a $6-\mathrm{V}$ battery was presented to the subject's right 
ear over a set of headphones. A set of eight red-light lenses for the presentation of the red-light stimuli was mounted horizontally on an $85 \times 46 \mathrm{~cm}$ background board. The lenses were $12 \mathrm{~mm}$ high and $25 \mathrm{~mm}$ wide, separated from each other by $25-\mathrm{mm}$ spaces. The entire array was positioned $60 \mathrm{~cm}$ from the subject at approximately the subject's eye level and placed on a table $74 \mathrm{~cm}$ high. A green-light lens for the green warning light was also positioned in the middle of the board $15 \mathrm{~cm}$ above the horizontal array. The timing sequence for the presentation of the stimuli was controlled by four Model 111C Hunter timers. Subjects seated at the table responded to the click by pressing a toggle switch located under the subject's right index finger on the table. The time of response to the click was measured by a Standard clock counter to the nearest $.01 \mathrm{sec}$.

\section{Procedure}

The task was a combination of a single and choice reaction time tasks. In the single reaction time task component, the subject responded to the auditory click by pressing the switch with his right index finger, which rested on the switch. In the choice reaction time task, the stimulus was one of a number of alternative red lights to which the subject responded by naming the light with a number so that the light at the extreme left was named "one," the next one from left to right was named "two," and so on. The presentation of the red light was preceded by a green light. The sequence of stimuli in each trial was as follows: the green light, followed by the click, followed by the red stimulus light. The interval between the click and the red stimulus light was always $.4 \mathrm{sec}$. The interval between the warning light and the click was $.6,1.6,2.6$, or $3.6 \mathrm{sec}$, so that the total interval between the warning light and the stimulus light was $1,2,3$, or 4 sec. The sequence of such intervals was completely randomized and constant across subjects.

The instructions stressed that the primary task was to respond with a verbal numerical response appropriate to a particular light. It was explained to the subject that the response to the click was a secondary task, the purpose of which was to see how distracting an effect it had on the speed and accuracy of naming the light. Actually, it was the time of response to the auditory stimulus that was of primary concern, and the choice reaction time was not even measured.

There were three experimental conditions. The number of alternative stimulus lights was two, four, or eight (so that the information value of the stimulus was one, two, or three bits of information, respectively). In the two- and four-alternative conditions, the light lenses that were not used were covered in black, so that only the used alternatives could be seen. In each condition, there were 20 trials, with the sequence of alternatives completely randomized. Each subject participated in all three conditions. Four subjects were run in each of the six possible permutations of conditions.

The first condition presented was preceded by 15 practice trials. The first five practice trials involved only naming the light without responding to the click. The next 10 practice trials involved both responses. The second and third condition were preceded by four light-naming trials and six practice trials involving both responses. There was a $5-$ min pause between conditions.

The time of response to the click was used as the dependent measure. The individual score in each of the three conditions was the mean reaction time across 20 trials.

\section{RESULTS AND DISCUSSION}

The mean simple reaction times when followed by a choice reaction time task involving two, four, or eight alternatives were $.309, .321$, and $.361 \mathrm{sec}$, respectively. The unifactorial analysis of variance yielded significant overall differences $[F(2,46)=6.374, p<.01]$. NewmanKeuls comparisons among treatment means yielded a significant difference between simple reaction times followed by two and eight alternatives $[F(1,23)=10.236$, $\mathrm{p}<.05]$ and between simple reaction times followed by four and eight alternatives $[F(1,23)=6.117, \mathrm{p}<.05]$.

The hypothesis that an increase in the number of alternatives (or the information value of the stimulus) in the choice reaction time task would result in a longer simple reaction time for a preceding stimulus was confirmed. It was demonstrated that the process of preparing for a choice reaction time task interferes with a simple reaction time task to a degree related to the number of equiprobable alternatives (or the information value of the stimulus) in the choice reaction time task. Preparation can be viewed as a process of commitment of attentional resources to a subsequent task that interferes with some concurrent process, such as a simple reaction time task. Such an outcome implies both a limited-capacity attentional system (not necessarily limited to a single channel) and at least partial parallel processing, so that a simultaneous occurrence of a simple reaction time task and preparation for a choice reaction time task mutually inhibit each other because of sharing of a limited attentional resource.

Use of the limited-capacity attentional system to prepare for an upcoming event has previously been inferred from subjects' performance after the relevant stimulus has occurred (Miller \& Anbar, 1981; Neely, 1977; Posner \& Snyder, 1975). The present study directly demonstrates the subjects' use of attention prior to the occurrence of the relevant stimulus by showing that preparing for the relevant event interferes with simple reaction time to a degree determined by the amount of preparation required by the relevant event.

The nature of the preparation process may require considerations beyond simple commitment of attentional resources to a subsequent task. While the present results support the hypothesis that subjects use more attention to prepare for an upcoming stimulus event when the number of alternatives increases, one is not sure how attention is specifically being used. Miller and Anbar (1981) have suggested that subjects use attention to activate $S-R$ pairs, thus making them more accessible and helpful in response selection. It is also possible that subjects prepare in a way that enables them to encode the stimulus at a faster rate (see Proctor, 1981, p. 305). The subject may be able to select a particular "strategy," depending upon the characteristics of the stimuli and responses and other variables in the experimental situation. Attention required for preparation of the reaction process may also be used to place the possible responses into short-term memory so that they are more accessible at the time of stimulus presentation. Logan (1979) 
found that short-term memory load created more interference with the choice reaction time task as the number of alternatives in the choice reaction time task increased. Since the subject is using short-term memory capacity for each of the two successive reaction time tasks at the time of the first reaction, an inhibition of both reaction processes would be expected to occur.

\section{REFERENCES}

Fitrs, P. M., \& Switzer, G. Cognitive aspects of information processing: I. The familiarity of S-R sets and subsets. Journal of Experimental Psychology, 1962, 63, 321-329.

Hick, W. E. On the rate of gain of information. Quarterly Journal of Experimental Psychology, 1952, 4, 11-26.

Hyman, R. Stimulus information as a determinant of reaction time. Journal of Experimental Psychology, 1953, 45, 188-196.

LogAN, G. D. On the use of a concurrent memory load to measure attention and automaticity. Journal of Experimental Psychology: Human Perception and Performance, 1979, 5, 189-207.
Miller, V., \& Anbar, R. Expectancy and frequency effects on perceptual and motor systems in choice reaction time. Memory \& Cognition, 1981, 9, 621-641.

NEELY, J. H. Semantic priming and retrieval from lexical memory: Roles of inhibitionless spreading activation and limitedcapacity attention. Journal of Experimental Psychology: General, 1977, 106, 226-254.

Posner, M. I., \& SNyder, C. R. R. Facilitation and inhibition in the processing of signals. In P. M. A. Rabbitt \& S. Dornic (Eds.), Attention and performance V. New York: Academic Press, 1975.

Proctor, R. W. A unified theory for matching-task phenomena. Psychological Review, 1981, 88, 291-326.

Sanders, A. F. Performance theory. In J. A. Michon, E. G. J. Eijkman, \& L. F. W. de Klerk (Eds.), Handbook of psychonomics (Vol. 2). Amsterdam: North-Holland, 1979.

Sмiтн, E. E. Choice reaction time: An analysis of the major theoretical positions. Psychological Bulletin, 1968, 69, 77-110.

Sмiтн, M. C. The effect of varying information on the psychological refractory period. Acta Psychologica, 1969, 30, 220-231.

(Received for publication April 5, 1982.) 